\title{
Economía y religiosidad. Clérigos propietarios en la diócesis de Astorga en los siglos $x$ y XI
}

\author{
Alberto Garín*
}

\begin{abstract}
RESUMEN ABSTRACT
La tradición historiográfica ha tratado a los obispos altomedievales de Astorga desde un punto de vista hagiográfico, sin interesarse por los aspectos económicos y políticos que les

rodeaban.

Nosotros mostramos la carrera religioso-política que desarrollaron estos obispos integrándose en la naciente administración de la monarquía leonesa, asi como el destacado papel que desempeñaron, como grandes propietarios, en la repoblación, entendida como un fenómeno de reorganización de la tierra.

The historiographic tradition has studied the high middle age bishops under the hagiographic point of view, putting no interest in the sorrounding political and economic aspects.

This is the description of the religious and political career developed by these bishops during their process of integration in the borning bureocracy of the Leon Monarchy, and their outstanding role played, as important landowners, in the repopulation, understood as a phenomenon of land reorganization.
\end{abstract}

La diócesis de Astorga se encuentra situada en el margen noroccidental de la meseta castellana, a medio camino entre León y Galicia, y comprende las comarcas de Valdeorras, la Cabrera, el Bierzo y el valle del Órbigo (figura 1).

\footnotetext{
- Becario del Museo del Louvre, sección Historia del Louvre.
} 


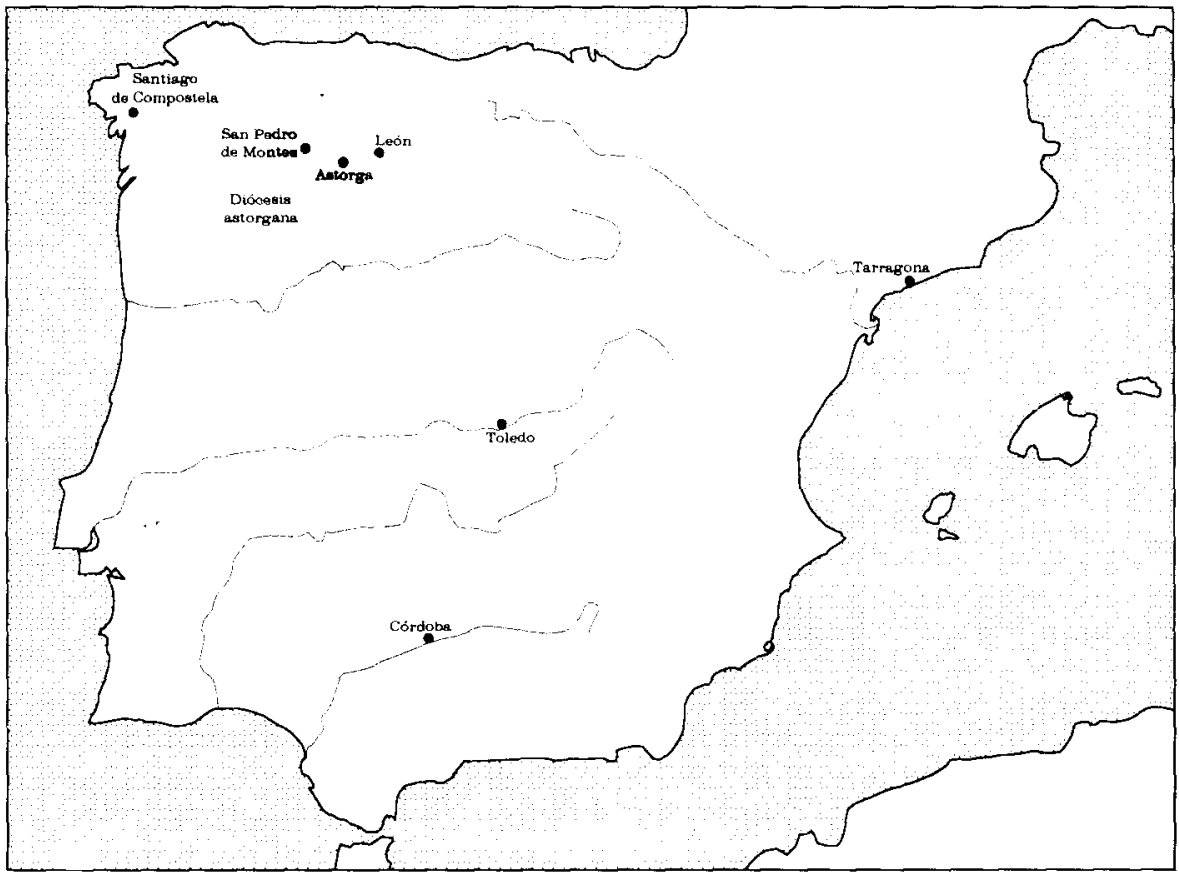

Figura 1. La diócesis de Astorga en los siglos centrales de la edad Media.

Su origen se remonta al Bajo Imperio romano, época en que el obispo astorgano dominaba todo el convento jurídico del mismo nombre. Permaneció vacante en los primeros tiempos de la conquista musulmana, hasta que a partir de mediados del siglo IX volvemos a encontrar a los obispos astorganos en la documentación medieval. En ese momento, la diócesis había sufrido una gran merma de su territorio por la creación de otras dos sedes episcopales, Oviedo y León, que por su condición de asientos de la Corte se habían visto privilegiadas en perjuicio de Astorga ${ }^{1}$.

Cualquier aproximación al estudio de la diócesis astorgana, en los siglos centrales de la Edad Media, se ve obligada a encararse con un grupo de figuras señeras, provinientes del mundo monástico. San Genadio, obispo y abad, y Sampiro, también obispo y cronista de reyes, pueden servir como ejemplo ilustrativo (junto a ellos estudiaremos otros casos), al tiempo que como marco cronológico del periodo que deseamos analizar.

1 Quintana Prieto, Augusto: Guia de la Diócesis de Astorga, Imprenta Carólica, León, 1960. 
En las semblanzas de estos personajes se ha venido destacando, por parte de los historiadores modernos, su profunda religiosidad, que unida a su alta sabiduría, les permitió progresar en las cortes de los reyes leoneses con los que convivieron. Sin embargo, creemos necesario mostrar la elevada posición económica que, por su origen, ya disfrutaban todos estos eminentes religiosos.

El caso de los clérigos propietarios de la diócesis de Astorga no es exclusivo ni de esta región, ni del tiempo que abordamos. Si echamos un breve vistazo a los siglos anteriores, encontramos casos parejos.

Los principales eruditos altomedievales han nacido en el seno de destacadas familias, se formaron en los mejores monasterios de la época y llegaron a desempeñar altos cargos tanto eclesiásticos como políticos (aunque veremos el matiz que todo esto adquiere en la Península lbérica).

Todas estas caracteristicas las encontramos reunidas en gentes como Isidoro de Sevilla y Agustín de Canterbury (que llegaron a ser obispos), Esmaregdo (abad de Saint Michel sur Meuse), Alcuino de York o Rhabano Mauro. Incluso, las mujeres, aunque no dejara de ser excepcional, podían llegar a alcanzar un puesto de privilegio, siempre que vinieran respaldadas por unos orígenes sólidos como es el caso de Hrotsvita, del monasterio de Gandersheim 2.

\section{SAN GENADIO}

Pero centrémonos en el ámbito astorgano en los siglos $x$ y $x$ I. Comenzaremos analizando el caso de san Genadio. Sólo a partir de conjeturas se ha tratado de hacerle nacer en la comarca del Bierzo, a mediados del siglo XI, en el seno de la familia del conde Gatón, el repoblador del Bierzo y Astorga, a quien también se le emparenta con la familia real astur-leonesa ${ }^{3}$.

Sin embargo, las primeras noticias de su vida nos las dio el propio Genadio cuando recuerda que profesó (es decir, vivió bajo una regla monás-

\footnotetext{
2 A modo de introducción sobre esta cuestión pueden consultarse las siguientes obras: Bremier, Emile: La Philosophie du Moyen Age, Albin Michel, Saint-Amand, 1971; Brooke, Christopher: Europa en el centro de la Edad Media (962-1154), Aguilar, 1973; Bruyne, Edgar de: Estudios de Estética Medieval, Gredos, Madrid, 1958, $n^{\circ}$ vols. 3; Gllson, Etienne: La filosofía en la Edad Media. Desde los orígenes patrísticos hasta el fin del siglo XIV, Gredos, Madrid, 1965; y LE GofF, Jacques: Los intelectuales en la Edad Media, Gedisa, Barcelona, 1986.

3 Para la biografía de San Genadio seguiremos, fundamentalemente, a Quintana Prieto, Augusto: El Obispado de Astorga en los siglos IX y X, Gráficas Cornejo, Astorga, 1968. Ver también Rodriguez LOPEZ, Pedro: Episcopologio asturicense, Astorga, 1907, $n^{2}$ vols. 2.
} 
tica) en el cenobio de Ageo 4 . Allí, tuvo ocasión de conocer la obra de San Fructuoso y San Valerio (dos figuras claves en el desarrollo de la vida cenobítica en la Alta Edad Media hispánica), siendo ésta una de las razones que le moveran a restaurar el monasterio de San Pedro de Montes, lugar donde residieron aquellos venerables santos.

Esta restauración debió comenzar hacia el 892 y fue concluida en el 895. Al año siguiente, 896, Ranulfo, obispo de Astorga, nombró a Genadio abad de San Pedro.

En 908, empujado por Alfonso III, Genadio acepta la silla episcopal astorgana, sucediendo a Ranulfo. Es posible que Genadio acompañase a este monarca en su última campaña por al-Andalus, cuando ya había dejado el trono por la presión de sus hijos. Muerto Alfonso III, Genadio se halla plenamente integrado en la curia de García l y, más tarde, en la del hermano de éste, Ordoño II.

Durante su pontificado, Genadio fundó o restauró numerosos monasterios en el Bierzo, entre ellos el de Santiago de Peñalba, situado, como el de San Pedro de Montes, en el valle del Oza.

A finales del 919, Genadio abandona el obispado sucediéndole su discípulo Fortis. En principio parece que se retiró al valle del Silencio, aunque siguió frecuentando la corte. A la muerte de Fortis, 932, y hasta la elección de un nuevo obispo, Salomón, Genadio se hizo cargo de la diócesis. Después volvió a enclaustrarse en el valle del Silencio, muriendo en Peñalba, probablemente el 25 de mayo del 936.

A partir de los datos conocidos y seguros, podemos esbozar la carrera que desarrolló Genadio: se incorporó al estado religioso en el monasterio de Ageo, donde adquirió una formación clásica, que pasa por la lectura de los Padres de la Iglesia. Alcanzó, primero, el abaciazgo, y, después, el obispado de Astorga, pasando a formar parte de la curia como consejero de los reyes, llegando, incluso, a integrarse en los ejércitos de uno de éstos.

Para el desarrollo de esta carrera religioso-política contó, desde el principio, con una posición acomodada. En este sentido resulta paradójico que sus biógrafos modernos traten por todos los medios de emparentarlo con la familia del conde Gatón y al tiempo lo describan como un hombre pobre, "simple seguidor de la regla de San Benito" 5 .

4 El llamado Testamento de San Genadio, documento en el que el propio santo da ciertos esbozos de su vida, ha sido publicado numerosas veces, si bien nosotros nos remitimos al apéndice 3 de la vida de San Genadio en Quintana Prieto, El Obispado en los siglos ix y x, op. cit., p. 207.

5 Quintana Prieto, El Obispado en los siglos ix $y x$, op. cit., p. 81. 
Contamos con al menos cuatro documentos donde Genadio hace entrega de bienes propios. Así, el 27 de mayo del 915, da al sacerdote Genemaro el monasterio de San Alejandro, eregido en tierras de Cabrera ${ }^{6}$. Al final del documento, donde exhorta para que nadie se levante contra su voluntad, hace explícita referencia a sus herederos.

El 8 de enero del 916, Genadio restaura el monasterio de Santa Leocadia de Castañeda, dotándole con los valles de Genestoso y Asinarios, que eran propiedad del santo ${ }^{7}$.

En el año 920 se fecha el llamado Testamento de San Genadio, al que ya hemos hecho referencia. Es muy conocido por la biblioteca que el santo dejó a los monasterios que había fundado, así como la organización que estableció para su uso. Pero, el entonces obispo también entregó una serie de propiedades a cada cenobio. En principio, los terrenos en los que está enclavado cada templo. Consideramos que esta cesión la haría Genadio en su calidad de obispo, puesto que está entregando los derechos propios del episcopado. A continuación, Genadio añade una serie de bienes muebles e inmuebles que eran de su propiedad. Ante esta entrega debemos plantearnos si estos bienes los habia recibido Genadio por su condición de obispo o se trataba de propiedades patrimoniales.

Para aclarar esta situación debemos retomar la restauración de los monasterios del valle del Oza, no sólo San Pedro de Montes, sino también Santiago de Peñalba y San Andrés de Montes. Todo esto habia comenzado treinta años antes de la expedición del documento que tratamos.

En su testamento, Genadio explica que él llegó junto con algunos colegas para restaurar el monasterio de San Pedro de Montes, hacia el 892. Pero, al tiempo, Ranulfo, quien ostentaba el obispado de Astorga en ese momento, también se atribuye el papel de restaurador de San Pedro ${ }^{8}$. Este doble protagonismo podría justificarse de la siguiente manera: cuando Genadio llega al valle del Oza con el objetivo de restaurar el monasterio de San Pedro, necesita el permiso del obispo Ranulfo, quien se lo concede. Reconstruidos los edificios, Ranulfo hace entrega de la iglesia del monasterio a éste ${ }^{9}$, es decir, cede los derechos que el episcopado tiene

A.H.N., Códices, $n^{2} 970$, fol. 400.

7 Publicado en FlóREZ, Henrique: España Sagrada. Theatro Geográphico-Histórico de la Iglesia de España. Tomo XVI de la Santa Iglesia de Astorga, Imprenta Gabriel Ramírez, Madrid, 1762, p. 426.

8 Quintana Prieto, El Obispado en los siglos $1 x$ y $x$, op. cit., p. 47.

Documento número 3 del Tumbo Viejo de San Pedro de Montes (a partir de ahora, TVM), publicado por Quintana Prieto, Augusto: Tumbo viejo de San Pedro de Montes, Centro de Estudios e Investigaciones "San Isidoro" (C.S.I.C.), León, 1971. 
sobre las iglesias de la diócesis, lo que confirmará, años después, Genadio en su testamento, al ostentar el solio episcopal.

Ahora bien, no estamos ante una simple restauración monástica, sino ante todo un programa de repoblación ${ }^{10}$. Ranulfo la comenzó a mediados del siglo Ix, con la repoblación de la villa de Castrelo (hoy Villanueva de Valdueza). Pero el auténtico revulsivo para atraer la población, fue la restauración del monasterio de San Fructuoso y San Valerio. Ranulfo está interesado, pues gran parte de sus bienes están en el valle del Oza. Por su testamento, Genadio demuestra que también tenía propiedades en este valle. Si estas fueran heredadas ${ }^{11}$, podriamos unir el motivo económico a otros objetivos religiosos que movieron a Genadio a recuperar San Pedro de Montes.

Es más, no debemos pensar que Genadio restauró el cenobio de Montes como primer jalón de un ambicioso plan de desarrollo monástico. Este sólo se desarrollaría veinte años después, cuando Genadio es obispo de Astorga y el monasterio de San. Pedro se ha puesto exitosamente en marcha.

Un último documento, fechado el 1 de octubre de 920, cuenta como Genadio entregó su villa de Laguna de Somoza a los monjes de Peñalba de Santiago y a los ermitaños del valle del Silencio. Al definir los límites del territorio, el obispo astorgano hace referencia a los términos que recibio de sus antepasados ${ }^{12}$.

Esto corrobora que Genadio tenía bienes patrimoniales antes de iniciar su carrera religioso-política, por lo que no es descartable que alguno de los otros bienes que entregara a lo largo de su vida fueran heredados.

Genadio se presenta, pues, como un gran propietario que, siguiendo la línea de los otros grandes propietarios de su tiempo, no tiene sus bienes concentrados, sino dispersos, en este caso por tierras del Bierzo, la $\mathrm{Ca}$ brera y la Somoza ${ }^{13}$, Incluso si aceptáramos como único bien patrimonial la villa de Laguna de Somoza, considerando que el resto las habría conseguido Genadio fruto de su actividad religioso-política, seguiríamos de-

10 Para Durany, esta repoblación se enmarca dentro de un programa más ambicioso impulsado por los monarcas astur-leoneses (DuRany Castrillo, Mercedes y Rodriguez González, María del Carmen: "El señorio de un monasterio berciano -San Pedro de Montes- en el valle de Valdueza (900-1300)" en Semana de Historia del Monacato, Monasterio de San Pelayo, Oviedo. 1982, p. 337).

No somos los primeros en apoyar esta idea. También se sugiere en DURANY CASTRILLO, Mercedes: San Pedro de Montes, el dominio de un monasterio benedictino de El Bierzo (Siglos IX al XIII), Institución «Fray Bernardino de Sahagún", León, 1977, p. 21.

12 B.N., Manuscritos, $n^{2} 4357$, Tumbo Negro de Astorga, doc. $n^{2} 136$.

13 Todas estas comarcas se situan dentro de la diócesis astorgana. 
lante de un gran propietario, como lo demuestra el estudio de Durany que define los diferentes tipos de villas citados en la documentación medieval como importantes centros de explotación agropecuaria ${ }^{14}$.

\section{LOS HEREDEROS DE GENADIO}

Salomón sucedió a san Fortis y san Genadio en el obispado de Astorga ${ }^{15}$.

Parece que Salomón ${ }^{16}$ había profesado en el monasterio de San Pedro de Montes, si bien no creemos (al contrario de sus biógrafos) que formara parte del grupo de monjes que llegaron junto a Genadio para restaurar el cenobio.

Ya en la España Sagrada ${ }^{17}$ se apuntó que había alcanzado el cargo de abad, aunque no en San Pedro, sino en el monasterio de los Santos Justo y Pastor de Compludo.

Llegado al obispado de Astorga hacia el 932, ese año ya le encontramos integrado en la curia de Ramiro II, acompañando al rey hasta Santiago de Compostela.

Sin embargo, Salomón no arraigó en la corte con la misma intensidad que sus predecesores hasta varios años después. Frecuentó los monasterios del valle del Oza, hasta donde llegó el propio monarca en el 940, y sólo fue a partir de entonces cuando Salomón aparece a menudo en la curia regia.

En septiembre del 946, se celebra el concilio de Irago, lugar que se ha situado en el valle de Compludo, presidido por Ramiro II y Salomón. Se trató la reorganización de la vida monástica de la diócesis astorgana, especialmente, la de la comarca del Bierzo.

A la muerte de Ramiro, Salomón aún se incorporaría a la corte de Ordoño III aunque moriría poco después, en ese mismo año 951.

Su carrera religioso-política se asemeja a la del restaurador de San Pedro de Montes. Habiendo ingresado en este monasterio y conociendo,

14 Durany Castrillo, Mercedes: “Las comunidades campesinas en el Bierzo medieval" en Estudios bercianos. Revista oficial del Instituto de Estudios Bercianos, $n^{2} 16$, I.E.B., Ponferrada, septiembre 1992, p. 110.

15 Recordemos que, a la muerte de Fortis y hasta la elección de un nuevo obispo, Genadio volvió a hacerse cargo del obispado.

16 Para la biografía de Salomón seguiremos, fundamentalemente, como con san Genadio, a

Quintana Prieto, el Obispado en los siglos ix y x op. cit.

17 Florez, España Sagrada. Astorga, op. cit., p. 41. 
como conocemos gracias al testamento de san Genadio, la biblioteca que poseía, Salomón pudo tener una amplia formación. Logró el cargo de abad antes de alcanzar el obispado de Astorga. A partir de ahí, se integró en la corte, donde consiguió gran influencia, como demuestra la continuada presencia del monarca en su diócesis.

Pese a no subir a los altares como sus colegas Genadio y Fortis, sus biógrafos modernos rodean siempre a Salomón con un halo de santidad y, evidentemente, de pobreza.

Sin embargo, en un documento fechado en el año $933^{18}$, Salomón hace entrega de la iglesia de San Esteban, con todas sus propiedades, al monasterio de los santos Justo y Pastor de Compludo. Si ponemos en relación esta donación con el concilio de Irago del 946, es probable que estemos ante un nuevo programa de repoblación, esta vez del valle de Compludo. De nuevo se trata de desarrollar una zona a partir de un monasterio, curiosamente otra antigua fundación de San Fructuoso, con el doble apoyo de la monarquía y los interesados de la zona, en este caso el obispo Salomón.

Las actuaciones de Ranulfo, Genadio y Salomón nos llevan a preguntarnos si su elección como obispos no estará motivada por el interés regio por la repoblación de los valles situados al sur de la Cordillera Cantábrica. De esta manera, los principales propietarios de la zona eran forzados a involucrarse en esta política repobladora, al tiempo que se les dotaba de los mejores medios para llevarla a cabo, integrándoles en la jerarquía eclesiástica.

Dentro de este planteamiento debemos enmarcar a Alporce, monje del valle del Oza, que llegó a ser abad del monasterio de Peñalba de Santiago en torno al $960^{19}$. Junto con sus hermanos Mirón (a quien se le denomina don Mirón) y Juan (que también llegó a ser abad de otro monasterio), compró y cedió sus propiedades en la Valdueza ${ }^{20}$. De nuevo un gran propietario integrado en la carrera eclesiástica, dentro de ese doble juego de obligación de amortizar sus bienes, al tiempo de dotarle de medios para desarrollarlos.

\section{SAMPIRO}

Sampiro, el cronista de reyes, será el máximo exponente de estos clérigos propietarios.

is B.N., Manuscritos, $n^{2} 4357$, Tumbo Negro de Astorga, doc. $n^{2} 280$.

19 Quintana Prieto, Augusto: Peñalba. Estudio sobre el monasterio berciano de Santiago de Peñalba, Nebrija, León, 1978, p. 26.

20 B.N., Manuscritos, $n^{2} 4357$, Tumbo Negro de Astorga, doc. $n^{2} 202$. 
Economía y religiosidad. Clérigos propietarios en la diócesis de Astorga...

Nacido en el Bierzo, se crió junto al futuro Vermudo II. Pese a que se le ha querido relacionar con el monasterio de Sahagún, parece ser que Sampiro sólo estuvo en el de San Miguel de Camarzana, donde conoció al prestigioso miniaturista Emeterio ${ }^{21}$. De alli huiría a Zamora ante la llegada de Almanzor, ciudad en la que probablemente se reunió con Vermudo II, ya rey único de León.

En el 990, Sampiro se encuentra en la corte en León y desde el año siguiente actua como notario, oficio que desempeñará hasta 1023, junto a otros destacados religiosos, los denominados por Pérez de Urbel monjes de palacio ${ }^{22}$, gentes probablemente educadas en monasterios, pero que no forzosamente siguieron niguna regla.

Junto a su labor notarial, Sampiro también desempeñó, ya en tiempos de Alfonso V, labores de merino y de sayón. Probablemente fue en esta época cuando elaboró aquella crónica que había de sernos conocida gracias a Pelayo de Oviedo y a la Crónica Silense ${ }^{23}$.

A través de los documentos que elaboró sabemos de su vasta formación que abarcaba desde un amplio conocimiento de la Biblia, la liturgia o la Regla de San Benito, a destacadas nociones de la legislación hispanogoda. Si a esta sabiduría unimos la destacada posición que ocupaba en la Corte, es de esperar que desempeñará un papel fundamental en el Concilio de 1017 donde se elaboró el Fuero de León ${ }^{24}$.

En 1023 abandona toda labor en la curia y poco después desaparece de la documentación cortesana. Probablemente su avanzada edad y una ceguera incipiente fueron importantes razones para dejar su puesto.

Sin embargo, cuando en 1034, Sancho III de Navarra ocupa la ciudad de León y la de Astorga, nombra a Sampiro obispo de ésta última. Pérez de Urbel define esta elección como fruto de una política «diabólicamente moderada" llevada a cabo por el navarro ${ }^{25}$. Es indudable que para granjearse la rápida amistad de los leoneses, Sancho III decidió colocar a personajes de prestigio en los puestos claves. De ahí, por ejemplo, la elección de Sampiro como obispo de Astorga. Pero la facilidad con la que dichos personajes aceptaron sus nombramientos parece indicar que los notables

\footnotetext{
21 Quintana Prieto, Augusto: El obispado de Astorga en el sigio xl, Gráficas Cornejo, Astorga, 1977, p. 84.

22 PÉREz de URBel, Justo: Sampiro. Su crónica y la monarquía leonesa en el s. $x$, C.S.I.C., Madrid, 1952, P. 33.

23 Pérez de URBel, Sampiro, op. cit., p. 135.

24 Quintana Prieto, El obispado en el s. XI, op. cit., p. 118.

25 Pérez de URBel, Sampiro, op. cit., p. 90.
} 
leoneses no se disgustaron en demasía por la presencia del navarro, que auguraba una ciera estabilidad. Quizás el calificativo de diabólico con el que caracteriza Pérez de Urbel la política de Sancho III no tenga demasiado sentido.

De cualquier modo, cuando Vermudo III recupera León, Sampiro permanece en su puesto e incluso le vemos integrado en la corte. Sin embargo, esta situación no dura mucho y en seguida encontramos a Sampiro lejos de la curia de Vermudo III ${ }^{26}$.

A la muerte de éste, en 1037, el nuevo monarca Fernando I, que no necesita granjearse ningún apoyo como le ocurriera a su padre Sancho III, puesto que es el legítimo rey, decidió renovar la iglesia leonesa, en especial para resarcirla de las pérdidas ocasionadas por los últimos años de inestabilidad. Para ello prescindirá de los más viejos obispos, como Sampiro, al que obligará a dejar el cargo hacia finales de 1040 o principios de $1041^{27}$.

El último documento de Sampiro data de finales de $1042^{28}$. En él, relata la ingratitud que le ha rodeado en los últimos años de su vida. Esta confesión amarga resulta contradictoria si la comparamos con las fórmulas de modestia que solía usar al suscribir los documentos. Se nos aparece así un hombre que no debió despreciar nunca la alabanza, lo que hace muy comprensible su aceptación del pontificado astorgano.

Sampiro morirá poco después y será enterrado en la catedral de León, junto a Vermudo $1{ }^{29}$.

La evolución religioso-política de Sampiro difiere algo de las que hemos estudiado precedentemete. No estamos seguros de que Sampiro llegara a profesar ninguna regla, pues el hecho de haberse educado en un monasterio, no implica que fuera monje. Probablemente fue su buena formación lo que hizo que fuera llamado por Vermudo II a su curia. Estamos dentro de una tradición que remonta a los tiempos hispanogodos, en la que el rey escoge entre sus nobles mejor educados para desempeñar los cargos de la administración (condes, obispos, notarios...). No debemos olvidar que todos los cronistas destacan en Vermudo II su apego a la tradición legislativa hispánica ${ }^{30}$.

26 Quintana Prieto, El obispado en el s. XI, op. cit.7, p. 141

27 PÉREZ DE URBEL, Sampiro, op. cit., p. 97 . También Servando, obispo de León y gran amigo de Sampiro, abandonó entonces su diócesis.

28 PEREZ DE URBel, Sampiro, op. cit., p. 476, ap. XIV.

29 Quintana Prieto, El obispado en el s. XI, op. cit., p. 158.

30 Casariego, Jesús E: Crónicas de los Reinos de Asturias y León, Everest, León, 1985. 
Economia y religiosidad. Clérigos propietarios en la diócesis de Astorga...

Sampiro llegaría al estado religioso mucho tiempo después y más a modo de recompensa, cuando fue elevado al obispado de Astorga.

Esto parece apuntar un cambio en la organización de iglesia leonesa. La jerarquía eclesiástica del siglo $x$ estaba formada por los propietarios de la zona donde radicaba el puesto a cubrir. En esos momentos se está produciendo la repoblación efectiva de la diócesis astorgana y es necesario dotar a sus instituciones de un patrimonio base. Pero a partir del siglo XI, los obispos son elegidos dentro de la burocracia interna de la curia. Sampiro no es un caso aislado. Pedro Gundulfiz, su sucesor en Astorga, también había sido notario regio. $Y$ todo apunta a que San Ordoño, que llegaría a Astorga algunos años después, desempeñó antes el cargo de notario ${ }^{31}$. Estos obispos burócratas ya no necesitan aportar sus bienes al obispado, sino defender el patrimonio de éste en irinumerables pleitos. Probablemente se ha cerrado el periodo de ocupación de la tierra ${ }^{32}$ dejando paso al de la reorganización de la población.

Sin embargo, esta hipótesis no debe hacernos olvidar que Sampiro seguía siendo un gran propietario. Sabemos que al final de sus días, su patrimonio era realmente destacado gracias a los beneficios obtenidos por los cargos cortesanos que ostentó. Esto le llevo a Pérez de Urbel a expresarse de esta manera: «El joven clérigo que un día llegó a la corte con las manos vacias contento de haber podido salvar su vida de los horrores de la invasión, habiase convertido en un hombre poderoso" ${ }^{33}$.

No es cierto. Cuando Sampiro llega a la corte huyendo de Almanzor ya cuenta en su haber con las propiedades heredadas de su padre: una villa en Sorribas del Bierzo, que habría de entregar a sus colegas de huída, para que estos fundaran un monasterio. A esta villa de Sorribas, poco después, Vermudo II añadiría una de sus propiedades, siendo el resultado de todo esto el monasterio de Carracedo ${ }^{34}$.

Ya dijimos antes como tras el concepto villa se está escondiendo una gran explotación agropecuaria. Esto echaría por tierra la idílica imagen de los biógrafos modernos de Sampiro que trataron de mostrárnosle en su adolescencia como un pobre campesino que crece a la sombra de un

\footnotetext{
31 Fuera de la diócesis astorgana es conocídisimo el caso de Diego Gelmírez, notario de la corte de Raimundo de Borgoña antes de ser elegido obispo de Compostela.

32 No se trata tanto de la ocupación física de un espacio, como de la absorción de los beneficios que éste genera en forma de rentas o impuestos.

33 PEREZ DE URBEl, Sampiro, op. cit., p. 72.

34 Martinez Martinez, Martin (ed.): Cartulario de Santa Maria de Carracedo, 992-1500. Volumen I: 992-1274, I.E.B., Ponferrada, p. 21, doc. 1.
} 
olvidado príncipe, el futuro Vermudo II. En realidad estamos ante dos jóvenes miembros de la clase propietaria, aquella que a golpe de privilegios fiscales terminará por configurar la nobleza leonesa ${ }^{35}$.

Concluyendo, durante los siglos $x$ y $x \mid$ podemos definir una carrera religioso-política a través de la cual los notables de la época accedían a los puestos claves de la jerarquía eclesiástica. Esta carrera comenzaba con la formación en un monasterio, para ir ocupando puestos intermedios hasta alcanzar el obispado y pasar a formar parte de la curia regia. Estamos ante una realidad que entronca perfectamente con la tradición de la monarquía hispanogoda, donde no existe la ruptura entre la Corona y la Iglesia que se da en la Europa del Norte.

Los clérigos que desarrollaron esta carrera religioso-política contaban con una posición económica desahogada que les permitía una dedicación plena a los estudios necesarios para alcanzar un acervo destacado de conocimientos.

Claro está, esto supone que junto a una economía saneada, contaban con una importante capacidad intelectual. Ambas cualidades unidas fue lo que les permitió progresar hasta el punto de que la acumulación de la cultura (en definitiva, la sabiduría medieval) se convertía en todo un poder político, que conllevaba un crecimiento de los patrimonios personales.

Sin embargo, eran estos patrimonios personales los que agrandaban aún más la importancia de los clérigos propietarios. Así, en el siglo x, las instituciones eclesiásticas se nutren de los bienes de sus miembros. En el siglo XI, esta tendencia no cesa, pero ahora las capacidades intelectuales más valoradas son las referidas al mundo de las leyes, como medio para proteger el patrimonio episcopal.

Curiosamente, esta combinación de desahogo económico y capacidad intelectual creo una aureola de prestigio en torno a los clerigos propietarios que les permitió ganar, en muchos casos, los altares.

35 Estepa Diez, Carlos: "La nobleza leonesa en los siglos XI y XIı" en Cuadernos, $n^{\circ} 1$, Centro de Estudios Astorganos "Marcelo Macías", Astorga, 1984. 